\author{
Bartosz Zając \\ Uniwersytet Łódzki
}

\title{
Esej audiowizualny - w stronę historii
}

$\mathrm{W}$ ostatnich latach w piśmiennictwie filmoznawczym, nie tylko zreszta akademickim, ale także na obszarze popularnej krytyki filmowej, niezwykle często pojawiają się teksty poświęcone zagadnieniu eseju filmowego ${ }^{1}$. Pojęcie to zostało oczywiście zaanektowane na obszar kina z literatury. Pozwoliło to przenieść część rozważań poświęconych esejowi literackiemu wprost na grunt badań nad filmem. W ten sposób badacze tej formy uzyskali szereg narzędzi ułatwiajacych opis tego oryginalnego zjawiska. Jednocześnie esej filmowy odziedziczył jednak po swoim literackim odpowiedniku problem związany z jego definiowalnością. Rozpiętość form literackich określanych mianem esejów, od Prób Montaigne'a, przez powieści Tomasza Manna czy choćby teksty Rolanda Barthes'a, sprawiła, że utrudnione - jeśli nie niemożliwe - stało się wskazanie inwariantnych wyznaczników gatunkowych tej formy.

Pojęciem eseju filmowego posłużył się prawdopodobnie jako pierwszy Hans Richter (w roku 1940) - definiując go jako nową formę dokumentalizmu, zdolna do przedstawiania abstrakcyjnych pojęć i idei. Jako przykład wskazywał filmy klasyków zaangażowanego społecznie dokumentalizmu przełomu lat dwudziestych i trzydziestych. Richter akcentował odchodzenie w tych filmach od chronologii w prezentowaniu wydarzeń i poświęcenie wierności nieupozorowanej rzeczywistości wczesnych aktualności filmowych, na rzecz wszelkich technik filmowych, które moga dopomóc w zilustrowaniu dyskursu autorskiego - a więc także fikcji - rekonstrukcji, inscenizacji, fabularyzacji ${ }^{2}$. Trzeba

${ }^{1}$ Wśród ważniejszych prac warto wymienić monografię Laury Rascaroli, The Personal Camera: Subjective Cinema and the Essay Film, London-New York 2009; ksiażke Timothy'ego Corrigana, The Essay Film: From Montaigne, After Marker, Oxford-New York 2011; Davida Montero, Thinking Images: The Essay Film as a Dialogic Form in European Cinema, Oxford-New York 2012; antologie Der Essay Film: Äesthetik und Aktuaität, red. Sven Kramer, Thomas Tode, Konstanz 2011; liczne teksty Nory M. Alter poświęcone eseistyce filmowej, w tym m.in. The Political In / visible in the Essay Film: Farocki's Images of the World and Inscriptions of War, [w:] Harun Farocki: Working on the Sight-Lines, ed. Thomas Elsaesser, Amsterdam University Press, Amsterdam 2004, s. 211-236; Translating the Essay into Film and Installation, "Journal of Visual Culture" 2007, Vol. 6, No. 1, s. 45-58.

${ }^{2}$ Hans Richter, Der Film Essay: Eine neue Form des Dokumentarfilms, [w:] Schreiben Bilder Sprechen: Texte zum essayistischen Film, red. Christa Blumlinger, Wien 1992, s. 195-198. 
tu dodać, że kino dokumentalne od czasów Griersonowskich, przynajmniej do momentu pojawienia się nurtu cinema verite w późnych latach pięćdziesiątych, na szeroka skale czerpało $\mathrm{z}$ tych technik, upodobniając filmy dokumentalne do kina fikcji (znamienny dla tej tendencji jest casus sztuki filmowej Flaherty'ego). W latach sześćdziesiątych w kinie fabularnym pojawiła się natomiast tendencja odwrotna, a więc upodabniania się, czy czerpania filmu fikcji z repozytorium technik właściwych kinu dokumentalnemu.

Dostrzegając strukturalne i formalne podobieństwa tych form teoretycy określani czasem mianem postmodernistycznych - Bill Nichols, Michael Renov, Trinh T. Minh-ha - zakwestionowali częściowo sam podział na dokumenty i filmy fikcjonalne ${ }^{3}$. Symptomatyczna była tutaj wypowiedź wietnamskiej teoretyczki i reżyserki Minh-ha: „opatruję swoje filmy etykietką dokumentów, tylko, gdy wysyłam je na festiwale" ${ }^{4}$ - w czym paradoksalnie zgadzała się z poglądami rewizjonistów, którzy broniąc zasadności posługiwania się terminem „dokumentalizm” wskazywali nie na kwestie formalne, ale na praktyki indeksowania dzieła, na to jak funkcjonuje ono w obiegu dystrybucyjnym, jaką funkcję nadaje mu autor, krytyka filmowa, czy wreszcie publiczność 5 .

Niezależnie jednak od bliskości fikcji i dokumentu - na poziomie rozwiązań warsztatowych i strukturalnych afiliacji - kluczowi twórcy utożsamiani z esejem filmowym byli niechętni fikcji i fabularyzacji, uprzywilejowując dyskurs: Wiertow fabułe uznawał za opium dla mas; podobne poglądy odnajdziemy w późniejszych wypowiedziach najważniejszych filmowych eseistów, Jean-Luca Godarda (zwłaszcza z okresu Le Groupe Dziga Vertov) czy Haruna Farockiego. Paradoksalnie, ci sami twórcy odpowiedzialni byli za pojawienie się w kinie lat sześćdziesiątych fabuł z dyskursywną dominanta ${ }^{6}$, które czerpiąc z koncepcji teatru epickiego Brechta starały się poddać syntezie kino fikcji i kino faktu.

Kino eseistyczne zwykło się więc utożsamiać z zacieraniem granic między fikcją i dokumentem, naciskiem na dyskurs i sięganiem po techniki określane mianem brechtowskich. Z pewnością każdy badacz poetyki eseju filmowego uzupełniłby tę listę szeregiem własnych wyznaczników. Ostatecznie jednak konkluzja pozostaje taka, że każdy pojedynczy eseistyczny tekst filmowy generuje swoja własna poetykę. Esej jest bowiem próba (fr. essai) polegająca na skrajnie subiektywnym podejmowaniu zagadnienia, mierzeniu się z nim $\mathrm{w}$ kategoriach osobistego doświadczenia odzwierciedlonego w stylistycznych idiosynkrazjach. Pozostaje więc paradoksem fakt, że znakomita większość opracowań na temat eseistyki filmowej stanowią te poświęcone poetyce. Można

${ }^{3}$ Zob. teksty w tomie Theorizing documentary, (red.) Michael Renov, Psychology Press, Minneapolis 1993.

${ }^{4}$ Trinh T. Minh-ha, From a Hybrid Place, [w:] eadem, Framer Framed, New York 1992, s. 139.

${ }^{5}$ Zob. Post-theory: Reconstructing Film Studies, Madison 1996. Tam zob. Jerrold Levinson, Nonfiction film and postmodernist skepticism; Noël Carroll, Moving pictures and the rhetoric of nonfiction film: two approaches; Carl Plantinga, Film, reality, and illusion.

${ }^{6}$ Zagadnienie to bada Tomasz Kłys w swojej książce Film fikcji i jego dominanty, Warszawa 1999. 
przypuszczać, że esej filmowy niewrażliwy na przemoc genologicznych taksonomii wywołuje jednocześnie $\mathrm{w}$ badaczach pragnienie wypracowania coraz bardziej subtelnych i wyrafinowanych strategii, które pozwoliłyby na opis nie sprowadzający się do prostych wyznaczników gatunkowych, a jednocześnie odkrywajacy wewnętrzne prawidłowości jakimi rządzi się ta forma.

Drugim problemem związanym przede wszystkim z krytyką filmową, która sięga po kategorię eseju filmowego, jest nadużywanie tego pojęcia. Wszędzie tam, gdzie napotykamy gatunkową hybrydyczność, formalne eksperymenty lub autorskie podejście, pojawia się niepostrzeżenie esej filmowy jako wygodna i przede wszystkim niezobowiązująca kategoria, która pozwala przyporządkować gatunkowo filmy wymykające się prostej klasyfikacji. Esej filmowy funkcjonuje tutaj jako obszerny sub-gatunek. W odróżnieniu od tekstów akademickich, popularna krytyka filmowa czuje się najczęściej zwolniona z obowiązku precyzowania, czym esej filmowy jest i jakie problemy wiążą się z sięganiem po ten termin. W ten sposób refleksja nad poetyką i teoria eseju filmowego zostaje zawieszona, wskazujacc jedynie na zbiór obiegowych haseł kojarzonych $\mathrm{z}$ tą formą.

Pojawia się więc pytanie o funkcjonalność kategorii eseju filmowego. Czy to określenie jest w jakikolwiek sposób operacyjne, czy w sposób obiektywny określa jakiś korpus filmów, które wspólnota widzów, krytyków, akademickich badaczy kina i samych twórców zgodziłaby się przyporządkować do zbioru filmowej eseistyki? Wreszcie czy można mówić o filmowej eseistyce, czy tylko o poszczególnych utworach? Czy można badać poetykę tej hybrydycznej formy, czy może należy przyznać, że stanowi ona ślepa plamkę w oku teorii gatunków i w refleksji nad „eseistyką" skazani jesteśmy tylko na niedające się uogólnić case studies?

Wobec zarysowanych powyżej trudności chciałbym w niniejszym szkicu zaproponować klasyfikowanie eseistyki w oparciu o typ / obecność / lub brak diegezy, a także rozwinięcie refleksji nad całkowicie niemal pomijanym obszarem historii tej formy filmowej.

Dlaczego akurat diegeza miałby się znaleźć w centrum rozważań nad odmianami filmowej eseistyki? Punktem wyjścia byłoby przyznanie, że esej filmowy jest przykładem kina dyskursywnego, a ściślej kina z dominanta dyskursu polifonicznego ${ }^{7}$, a więc takiego, które przedstawia autorski wywód nie tyle $\mathrm{w}$ formie logicznie ustrukturowanej, ograniczającej się do prostej ilustracji tez, ile właśnie otwartej, wewnętrznie zdialogizowanej, dynamicznej - pozwalającej widzowi na aktywne współtworzenie, czy wręcz „współpisanie”. Esej filmowy byłby zatem rodzajem kino-pisania, refleksji która w sposób dialektyczny rozwija myśl formując ja przy pomocy słów, dźwięków i obrazów. Dla rozwoju tak rozumianego kina kluczowe znaczenie miał montaż asocjacyjny zaproponowany przez sowiecką szkołę w latach dwudziestych, przypomniany w latach pięćdziesiątych i sześćdziesiątych w filmach francuskich autorów związanych

${ }^{7}$ Kategorię filmów z dominantą dyskursu polifonicznego wprowadził T. Kłys, op. cit., s. 156. 
głównie z tzw. „lewym brzegiem” i z powodzeniem wykorzystywany w eksperymentalnych filmach politycznych przynajmniej do lat osiemdziesiatych ${ }^{9}$.

Analizując Szósta część świata Dzigi Wiertowa, sztandarowy przykład kina generujacego audiowizualny dyskurs za pomoca montażu asocjacyjnego, Mirosław Przylipiak zwrócił uwage, że przy niezwykłej precyzji w budowaniu filmowego dyskursu, film Wiertowa rozbija jednocześnie diegezę. „Ciag obrazowy nie ma służyć rejestracji ani pokazaniu świata, lecz ilustracji słów, stąd film nie ma właściwie diegezy, świata przedstawionego, pomiędzy poszczególnymi ujęciami nie istnieje żadna więź, ba nawet namiastka więzi czasoprzestrzennej. Łączy je natomiast, w sposób bardzo wyraźny, logika myśli"10. Wiertow, podobnie jak Eisenstein w swoich wczesnych filmach, rezygnował $\mathrm{z}$ indywidualnego bohatera i zamiast tego przedstawiał $\mathrm{w}$ swoich awangardowych dokumentach problemy, zagadnienia. W eksperymentach z filmowym dyskursem poszedł zreszta dalej od autora Strajku, uwalniajacc wywód od fikcyjnej anegdoty, która mimo braku indywidualnego bohatera pozwalała na zachowanie względnej spójności diegetycznej. U Eisensteina najbardziej wyraziste dyskursywnie partie maja charakter wstawek rozbijajacych diegezę. W przypadku Wiertowa diegeza często w ogóle się nie konstytuuje, tak, że jako widzowie obcujemy z czystym dyskursem. W przyszłości najważniejsi eseiści filmowi, Alain Resnais, Agnes Varda, Chris Marker, Guy Debord, Jean-Luc Godard czy Harun Farocki będa konstruowali swoje filmy na podobnej zasadzie. Kino-pisanie będzie w ich filmach szło w parze $\mathrm{z}$ radykalna fragmentaryzacją świata przedstawionego aż do granic całkowitego rozbicia diegezy.

W tym miejscu trzeba oczywiście wspomnieć, że czym innym jest diegeza w kinie fikcji, a czym innym ta właściwa kinu niefikcjonalnemu, do którego zaliczylibyśmy film Wiertowa i znakomitą większość późniejszych esejów filmowych. W pracy Ideology and the Image Bill Nichols wskazał, że podczas gdy w przypadku filmów fikcji za diegezę należałoby uznać „zachowujące autonomię uniwersum czasoprzestrzenne", to w przypadku kina niefikcjonalnego diegezą byłoby, jak to określa Nichols, „uniwersum konceptualne”11. Innymi słowy, w przypadku kina

${ }^{8}$ „Resnais, Varda i Marker wraz ze współpracownikami tworzyli razem grupę określaną czasem mianem «lewego brzegu» nowej fali, w odróżnieniu od "prawego brzegu» związanego głównie z pismem «Cahiers [du Cinéma]» (Godard, Truffaut, Rivette, Rohmer, Chabrol, Doniol-Valcroze). Rozróżnienie to nie jest już dziś tak czytelne jak wydawało się być w 1959-1960., ale grupa «lewego brzegu» (która faktycznie mieszkała na lewym brzegu [Sekwany]) odcinała się od grupy "prawego brzegu» z uwagi na swoje wyraźnie lewicowe poglądy (stąd też wywiązały się później między tymi grupami spory natury estetycznej i politycznej) i reprezentowanie bardziej aktywnej postawy społecznej, jak również bliższy związek z modernistycznymi nurtami w sztuce, zwłaszcza w literaturze (powieściopisarka Marguerite Duras i Alain Resnais współpracowali nad dwoma filmami Resnais); stąd też [u autorów «lewego brzegu»] wynikała - przynajmniej w tym okresie - troska o formalne innowacje”. Przypis redakcyjny w antologii Cahiers du Cinéma. The 1950s: Neo-Realism, Hollywood, New Wave, ed. Jim Hillier, Cambridge, MA 1985 (przyp. 8, s. 70).

${ }_{9}^{9} \mathrm{Na}$ przykład kino sytuacjonistyczne, filmy kolektywu Dziga Vertov Group, III kino Fernando Solanasa i Octavo Getino, jak również filmy Haruna Farockiego.

${ }^{10}$ Mirosław Przylipiak, Poetyka kina dokumentalnego, Gdańsk-Słupsk 2004, s. 110.

${ }^{11}$ Bill Nichols, Ideology and the Image: Social Representations in the Cinema and Other Media, Bloomington 1981, s. 183. 
fikcji diegeza tożsama jest ze światem przedstawionym, wyłanianie się diegezy oznacza zaś powoływanie do życia spójnej ontologicznie filmowej rzeczywistości. Tymczasem w przypadku kina niefikcjonalnego, zwłaszcza w dokumentach objaśniajacych, diegeza - „światem”, w którego regułach funkcjonowania widz musi się orientować, aby odbiór filmu nie został zaburzony i aby film był czytelnym komunikatem - pozostaje retoryczna „przestrzeń filmu” - bliższa znaczeniu pojęcia dyskursu niż klasycznej diegezy. Z tego zresztą względu Nichols wprowadza rozróżnienie na diegezę i „diegezę". Choć obie odnoszą się do kina dokumentalnego, pierwsza byłaby tożsama z rzeczywistościa profilowa adresowana silnie w kinie niefikcjonalnym, druga natomiast, określana przez Nicholsa zastępczo mianem „konceptualnej fikcji”, stanowiłaby wspomnianą przestrzeń dyskursywna filmu, w której bezpośrednio manifestuje się autorski wywód ${ }^{12}$.

Przechodzac teraz do typologii form eseistycznych, za eseje filmowe sensu stricto proponuję uznać filmy, w których nie wyłania się żaden fundament diegetyczny, w których jedyna przestrzenia jest dyskurs - filmy montażowe, w których relacja między poszczególnymi obrazami, słowami i dźwiękami nie pozwala określić jakiegoś uprzywilejowanego ontologicznie centrum, podobnie jak ma to miejsce w kolażu - obrazy nie sa tu ilustracją dyskursu budowanego za pomoca słów, jak w klasycznych kronikach filmowych, ale tworza wraz z nimi wspólną audiowizualna przestrzeń pisma; z kolei filmy eseistyczne (niektóre dokumenty cinéma verité Ophülsa, Herzoga, ale także filmy nowofalowe Godarda, Klugego, Makavejeva czy Oshimy) nie rezygnowałyby z konstruowania świata przedstawionego, fabularyzując fakty, które łączyłaby najczęściej jakaś fikcyjna lub rzeczywista postać. Eseistyczność funkcjonowałaby tu na zasadzie dominanty, argumentacyjnego ustrukturowania diegezy i rozgrywających się w niej wydarzeń. Do trzeciej grupy chciałbym zaliczyć tzw. filmy interfejsowe, w których diegeza ograniczona jest zazwyczaj do jednego, specyficznego miejsca - pracowni montażowej, w której niejako „na naszych oczach” konstruowany jest przez autora audiowizualny dyskurs. Do grupy tych filmów zaliczyć można m.in. Scenariusz do filmu „Pasja” Godarda, Interface Farockiego, niektóre dokumenty Orsona Wellesa czy Level Five Chrisa Markera.

W przypadku najbardziej radykalnych formalnie esejów filmowych przynależących do pierwszej grupy mielibyśmy do czynienia z sytuacją, w której nie konstytuuje się ani diegeza w tradycyjnym rozumieniu (kontinuum czaso-przestrzenne), o której pisał Mirosław Przylipiak, ani „diegeza” jako „uniwersum konceptualne”, o której mówił Bill Nichols. Diegeza konceptualna opiera się bowiem na spójności autorskiego wywodu, jego semantycznej stabilności. Z kolei tym, co zaburza „diegeze”, sa - zdaniem Nicholsa - wszelkie zabiegi utrudniajace lekturę, pozostawiające widza z obrazem w jego wieloznaczności. Jeśli w kinie fikcji postać narratora zwracajacego się bezpośrednio do widza może diegezę burzyć, to w przypadku kina dokumentalnego to właśnie narrator scala „diegeze”, a rozbija ja jego milczenie, które wprowadza niepewność u odbiorcy co do znaczeń implikowanych przez pozostawiony bez komentarza

${ }^{12}$ Ibidem, s. 184-185. 
materiał audiowizualny ${ }^{13}$. W przypadku esejów filmowych mamy do czynienia z taką właśnie sytuacja - narrator wystawia nas często na próbę, konfrontuje z labiryntem tekstu nie dajac, jak ma to miejsce w klasycznych dokumentach objaśniających, czytelnych wskazówek lekturowych. Nie musi to zresztą dotyczyć wyłącznie obecności / braku komentarza ponadkadrowego, ale wszelkich strategii narracyjnych, które rozmnażaja sensy implikowane przez obraz zamiast je redukować i stabilizować. Intencją autorów esejów filmowych jest właśnie swoista niekonkluzywność, otwartość i dialogizm, a więc wszystko to, co wprawia tekst w ruch, narusza jego strukture i ostatecznie zaburza orientacje widza w „konceptualnym uniwersum” filmu. W zamian odbiorca zostaje zaproszony, a czasem zmuszony do podjęcia ryzyka indywidualnej lektury śladem tropów pozostawionych w tekście przez autora.

Pojęcie diegezy nie musi służyć wyłącznie analizie tekstualnej, badaniom poetyki kina. Może się też okazać funkcjonalne w zakresie refleksji historyczno-filmowej. Thomas Elsaesser w artykule poświęconym nowej historii filmu przypomina, że diegeza rozumiana jako „kombinacja miejsca, przestrzeni, czasu i podmiotu"14, nie jest kategorią ahistoryczną, że na różnym etapie rozwoju medium filmowego wrażenie obecności filmowego świata osiagano posługując się odmiennymi strategiami zwrotu wobec widza, inaczej konstruując filmowe światy; inna postać przyjmowała diegeza w okresie kina atrakcji, inaczej w okresie klasycznym, a jeszcze inne formy diegezy pojawiają się w kontekście spotkań filmu z tzw. nowymi mediami. Badanie historii filmu powinno więc, zdaniem Elsaessera, uwzględniać szereg czynników składających się na sytuację doświadczenia kinowego, wykraczając tym samym znacznie poza analize tekstualna - ta bowiem pomija rozpoznanie uwarunkowań odbiorczych, które pozwalaja nam ocenić w jaki sposób widz faktycznie doświadczał kina, w oparciu o jakie procedury odbiorcze współkonstytuował w trakcie seansu filmowe światy.

Propozycja Elsaessera przedstawiona na przykładzie wczesnego kina jest $\mathrm{w}$ istocie próbą stworzenia modelu historiografii kina pozwalajacego na opis wszelkich fenomenów filmowych, przy założeniu ewolucyjnego charakteru filmowej diegezy.

Zmierzałbym tu do konkluzji - pisze Elsaesser - że kolejne fazy kina, ale też relacje kina do innych form medialnych, takich jak telewizja, sztuka wideo i media cyfrowe, moga być mapowane przez analizowanie ich rozmaitych i odrębnych światów diegetycznych, które obejmuja zarówno aparat techniczny, jak i dyspozytywy umysłowe, ale które również sa zależne od czasowych, przestrzennych i enuncjatywnych lokalizatorów oraz aktywatorów wspólnie konstytuujących specyficzne „ontologie” tych światów ${ }^{15}$.

Diegeza w ujęciu Elsaessera obejmująca aparat techniczny i dyspozytywy umysłowe wykracza znacznie poza tradycyjne rozumienie diegezy, a nawet to rozszerzone, zaproponowane przez Billa Nicholsa. U autora Ideology

${ }^{13}$ Ibidem, s. 184.

${ }^{14}$ Thomas Elsaesser, Nowa historia filmu jako archeologia mediów, przeł. Grzegorz Nadgrodkiewicz, „Kwartalnik Filmowy” 2009, nr 67-68, s. 29.

${ }^{15}$ Ibidem, s. 35. 
and the Image diegeza pozostawała właściwościa tekstu. Sądzę, że bardziej zasadne byłoby tu posłużenie się innym pojęciem posiadajacym długą tradycję w myśli filmowej, a mianowicie dyspozytywem. Z propozycja badania historii kina przez prymat ewolucji jego dyspozytywów wyszedł kilka lat temu Frank Kessler. Autor wskazywał, że konceptualizacja dyspozytywu w optyce krytyki ideologicznej lat siedemdziesiatych (przede wszystkim w teorii aparatu) nie uwzględniała jego historycznych przemian, prezentując dyspozytyw jako „transhistoryczna normę"16. Jeśli dyspozytyw obejmuje triadę złożona z technologii, tekstu (formy filmowej z właściwym jej sposobem adresowania widza) i szeregu czynników składających się na sytuację odbiorczą (spectatorship), to należy uznać, że „w różnych momentach historii medium może wyprodukować szczególną i (tymczasowo) dominujaca konfigurację technologii, tekstu i modelu odbioru"17. Kessler zwraca też uwagę, że historia filmu pisana przez pryzmat odmiennych dyspozytywów brałaby pod uwage różne sposoby wykorzystania tego samego tekstu w zmiennych kontekstach wyświetlania czy też $\mathrm{w}$ różnych ramach instytucjonalnych. Autor powołuje się w tym miejscu na Rogera Odin, który wskazywał, że inaczej czytany będzie film fikcji w kinie i w sali wykładowej w ramach kursu studiów filmoznawczych ${ }^{18}$.

W badaniu dyspozytywu należy więc uwzględnić zagadnienia związane z szeroko pojętą recepcja, którą warunkuje nie tylko wykorzystana technologia i specyficzna architektura, w ramach której film jest wyświetlany, lecz także pozycja odbiorcza determinowana m.in. przez zmienne historycznie i zależne od rozmaitych kontekstów instytucjonalnych (produkcyjnych, tych związanych z określonymi sposobami prezentacji filmu, ale też uwzględniajacych np. role otaczających filmy dyskursów ${ }^{19}$ ) nawyki i kompetencje odbiorcze.

Wróćmy teraz do eseju filmowego, aby sprawdzić, jak dalece funkcjonalne byłoby badanie jego historii przez pryzmat odmiennych dyspozytywów. Jak wskazywałem wcześniej, analiza historyczna zajmuje marginalne miejsce w korpusie prac poświęconych temu sub-gatunkowi.

Kanoniczna historię eseju filmowego, w podobnych wariantach powracajaca w niemal każdym opracowaniu poświęconym tej formie, można sprowadzić do kilku punktów. Genealogicznym źródłem pozostaje niezmiennie sowiecka szkoła

${ }^{16}$ Frank Kessler, The Cinema of Attractions as Dispositif, [w:] Cinema of Attractions Reloaded, ed. Wanda Strauven, Amsterdam 2006, s. 61.

${ }^{17}$ Ibidem.

${ }^{18}$ Ibidem.

${ }^{19} \mathrm{~W}$ swoich badaniach nad historią kina jako historia dyspozytywów Kessler odwołuje się, z jednej strony, do koncepcji dyspozytywu rozwijanej na gruncie teorii filmu, a z drugiej - do tej zaproponowanej przez Michela Foucault. „Tym, co próbuję oznaczyć za pomoca tej nazwy, jest, po pierwsze, zdecydowanie heterogeniczny ansambl, zawierajacy dyskursy, instytucje, zabudowę architektoniczna, regulaminy, prawa, przepisy administracyjne, wypowiedzi naukowe, twierdzenia filozoficzne, moralne, filantropijne; krótko mówiąc: to, co powiedziane, jak i to, co niepowiedziane; oto właśnie elementy dyspozytywu. Sam w sobie dyspozytyw jest siecią, którą można ustanowić między tymi elementami”. Cyt. za: Magdalena Nowicka, 'Urzadzenie', 'zastosowanie', 'uktad'... kategoria dispositif u Michela Foucaulta, jej ttumaczenia i ich implikacje dla postfoucaultowskich analiz wtadzy, „Przegląd Socjologii Jakościowej” 2011, Vol. 7, nr 2, s. 97. 
montażu i symfonie miejskie. Następnie autorzy wskazują teksty krytyczne, teoretyczne i manifesty, które sproblematyzowały zjawisko eseju filmowego - wspomniany wcześniej artykuł Hansa Richtera (1940), manifest Kamera-pióro Alexandre’a Astruca (1948) i recenzje filmów Chrisa Markera pióra André Bazina $(1958)^{20}$. Pojawienie się filmów Chrisa Markera, a także Alaina Resnais i Agnes Vardy to - zdaniem wielu badaczy - moment narodzin „eseju właściwego”. Potem przychodzi nowa fala francuska z refleksywnymi fabułami Jean-Luca Godarda. Miejsce reżysera na osi rozwoju filmowej eseistyki puentuje niezmiennie cytat z wywiadu, w którym Godard określa tak właśnie swoje filmy ${ }^{21}$. Niektórym autorom daje to pretekst do rozszerzenia kategorii eseju filmowego nie tylko na cała twórczość Godarda, ale w ogóle na nową falę ${ }^{22}$. Po nowofalowym przewrocie w kinematografii nie ma już zgody co do tego, czym jest esej filmowy. Panuje raczej pełna dowolność. Filmoznawcy akademiccy, krytycy filmowi i widzowie zabierajacy głos na formach internetowych określaja tym mianem niemal wszystkie dokumenty autorskie, wszelkie formy przekraczajace ramy gatunkowe i rodzajowe, zamieszczane w Internecie wideo-recenzje i wideo-diariusze.

Zreferowana „historia eseju filmowego” zasługuje raczej na miano kroniki - w istocie nie stanowi ona próby interpretacji zmiennych losów tej formy filmowej, a jedynie szereguje fakty w układzie chronologicznym, ograniczajac się - jak wiele historii filmu - do wskazania najważniejszych twórców, dzieł i tekstów. Wyjątkiem sa fragmenty monografii Timothy'ego Corrigana. W rozdziale dotyczacym historii tej formy autor wskazuje między innymi na rolę udźwiękowienia filmu kluczowa z punktu widzenia roli, jaka w esejach filmowych odgrywa komentarz ponadkadrowy. Corrigan wymienia też czynniki instytucjonalne i społeczne: powstanie klubów filmowych (głównie francuskich) w latach dwudziestych i trzydziestych, a wraz z nimi narodziny „kultury filmowej” i nowego widza gotowego na odbiór ambitnych filmów, w tym również esejów filmowych ${ }^{23}$.

Zdaniem Corrigana, mimo że wiele filmów zrealizowanych w latach dwudziestych i trzydziestych wpisuje się w dziedzictwo audiowizualnej eseistyki, konieczne jest wskazanie punktów zwrotnych - kluczowych momentów w ewolucji tej formy. Według Corrigana jest to rok 1940. Wówczas to miałaby się dokonać synteza charakterystycznych dla eseju filmowego struktur narracyjnych i trendów stylistycznych. W tym samym okresie esej filmowy staje się forma samoświadoma - rozpoznawalna, a samo pojęcie wchodzi do powszechnego

${ }^{20}$ H. Richter, Der Film Essay...; Alexandre Astruc, Narodziny nowej awangardy: kamera-pióro, przeł. Tadeusz Lubelski, [w:] Europejskie manifesty kina. Od Matuszewskiego do Dogmy. Antologia, wyb., wstęp i oprac. Andrzej Gwóźdź, Warszawa 2002, s. 62-68; André Bazin, Marker's Lettere de Sibérie, [w:] André Bazin. French Cinema from the Liberation to the New Wave, 1945-1958, ed. and transl. Bert Cardullo, New Orleans 2012, s. 302-306.

${ }^{21}$ Zob. Sławomir Bobowski, O eseju filmowym. Na przyktadzie „Iluminacji” Krzysztofa Zanussiego, „Studia Filmoznawcze” 1991, vol. X, red. Jan Trzynadlowski, s. 171-172.

${ }^{22}$ „Podkreślamy: «nowa fala» wprowadziła do genologii filmowej nowy gatunek, esej. Utwory reżyserów tej formacji posiadają cechy strukturalne analogiczne do eseju literackiego"; S. Bobowski, op. cit., s. 172.

${ }^{23}$ Timothy Corrigan, The Essay Film: From Montaigne, After Marker, Oxford-New York 2011, s. $57-58$. 
użytku. Jest to też moment rozwoju filmologii francuskiej, która kładła nacisk na społeczną rolę kina, kluczowa dla lewicowo zorientowanych eseistów filmowych. Także w 1940 Andre Malraux formułuje konstatacje o możliwości indywidualnej ekspresji w kinie, a Hans Richter publikuje swój artykuł, w którym posługuje się terminem „esej filmowy”24.

Corrigan wspomina też w swojej pracy o tzw. „historii prekursorów eseju filmowego" (precursive history). Zalicza do niej wczesne kino o charakterze edukacyjnym czy wręcz dydaktycznym, trawelogi, filmowe wykłady naukowych tez. Miały one stanowić zapowiedź dojrzałej formy eseju filmowego stanowiącej mariaż dyskursu artystycznego i naukowego ${ }^{25}$.

$\mathrm{Na}$ interesujący trop w historii eseju filmowego zwraca też uwagę Paul Arthur. Jego zdaniem dla pojawienia się tego sub-gatunku kluczowe znaczenie miały nowe modele $\mathrm{w}$ historiografii i towarzyszace jej nowe reprezentacje w kinie dokumentalnym jakie zaczęły się pojawiać w następstwie wydarzeń II wojny światowej. „Odwracając znane upomnienie Adorna - pisze Arthur - że po Auschwitz pisanie poezji powinno być niemożliwe, to właśnie po Holokauście - stanowiacym w naszej erze ostateczny test dla indywidualnego świadectwa w kolektywnej traumie - esej filmowy uzyskuje wyrazisty estetyczny kształt i cel moralny"26.

Zdaniem Corrigana, esej filmowy stanowił zatem odpowiedź na pytania, z jakimi musiała się po II wojnie światowej zmierzyć klasyczna historiografia i realistyczne kino dokumentalne; pytania o strategie reprezentacji tego, co Hayden White określił mianem „zdarzeń modernistycznych” czy „holokaustycznych"27. Krew zwierzat (Le Sang des bêtes, 1949) Georgesa Franju, pierwsze eseje filmowe Alaina Resnais powstałe w latach pięćdziesiątych: Guernika (Guernica, 1950), zrealizowane wspólnie z Chrisem Markerem - Posagi też umieraja (Les Statues meurent aussi, 1953) i Noc i mgta (Nuit et brouillard, 1955), w równym stopniu problematyzuja tragiczne wydarzenia w najnowszej historii - kolonializm, Holokaust, zagładę nuklearną ludności Hiroszimy i Nagasaki, co kwestię możliwości ich filmowej reprezentacji.

Trzecie odstepstwo od kanonicznej historii eseju filmowego napotykamy w pracach Nory M. Alter, która w swoich badaniach proponuje case studies rekonstruujace złożone sieci kontekstów determinujacych powstanie, kształt i odbiór poszczególnych filmów - kontekstów o charakterze historycznym, społecznym, instytucjonalnym, politycznym, a czasem po prostu biograficznym ${ }^{28}$.

${ }^{24}$ Ibidem, s. 63.

${ }^{25}$ Ibidem, s. 55-56.

${ }^{26}$ Paul Arthur, Essay Questions: From Alain Resnais to Michael Moore, "Film Comment" 2003, Vol. 39, No. 1, s. 61.

${ }^{27}$ Hayden White, Zdarzenie modernistyczne, przeł. Maciej Nowak, [w:] Hayden White, Proza historyczna, red. Ewa Domańska, Kraków 2009, s. 283-313.

${ }^{28}$ Nora M. Alter, Projecting History: Non-fiction German Cinema: 1967-2000, Ann Arbor 2002; The Political In/visible in the Essay Film: Farocki's Images of the World and Inscriptions of War, [w:] Harun Farocki, Working on the Sight-Lines, ed. Thomas Elsaesser, Amsterdam 2004, s. 211-236; Marcel Ophuls' November Days: German Reunification as Musical Comedy, "Film Quarterly" 1997, Vol. 51, No. 2, s. 32-43. 
Podejście wykorzystywane przez Alter uzupełnia propozycję historiografii dyspozytywów filmowych, która chciałbym zastosować w badaniach eseju filmowego. W każdym bowiem przypadku historyczna analiza dyspozytywów w ramach, których funkcjonowały i ewoluowały eseje audiowizualne, musi też uwzględniać „mikro-historie” poszczególnych realizacji.

Jednym z wyznaczników eseju, tak zreszta literackiego, jak i filmowego, jest jego refleksywność, przez która należałoby rozumieć problematyzowanie języka, możliwości (i granic) reprezentacji, wreszcie samego medium, w którym eseistyczna myśl się manifestuje. Eseista nie ucieka się do prostej prezentacji podejmowanego zagadnienia, ale próbuje, mierzy się z nim, nie roszcząc sobie praw do obiektywizacji formułowanych sądów. Pozostaje subiektywny, zwracając uwagę na miejsce, z którego przemawia. Dlatego też wszystkie eseje - w sposób implicytny lub eksplicytny - wskazują na medium, jakim sie posługuja: słowo, obraz fotograficzny, obraz filmowy, telewizyjny, obraz wideo. Odpowiadają im różne episteme, różne media, wreszcie też odmienne dyspozytywy. W niniejszym szkicu chciałbym jedynie przedstawić zarys historii eseju audiowizualnego badanego przez pryzmat dyspozytywów właśnie. Ponieważ poszczególne formy eseistyczne i odpowiadajace im dyspozytywy dominowały w określonych kontekstach historycznych, ich genealogię można przedstawić $\mathrm{w}$ porządku chronologicznym. Mimo to wiele z nich powracało na przestrzeni kolejnych dekad przekraczajacc tym samym taką linearną narrację.

W ramach tego, co Timothy Corrigan określił mianem „historii prekursorów eseju filmowego" można wyróżnić dwie formy kluczowe dla rozwoju późniejszego eseju filmowego. Do tej grupy zaliczyłbym atlasy wizualne, w tym przede wszystkim atlas Mnemosyne (1924-1929) Aby'ego Warburga, awangardowe foto-eseje powstające pod koniec lat dwudziestych w Republice Weimarskiej (1928-1930)29, fotograficzne albumy montażowe w rodzaju Deutschland, Deutschland über alles Kurta Tucholsky'ego i Johna Heartfielda (1929) czy War Primer (1955) Bertolta Brechta, jak również eseistyczny trawelog Chrisa Markera Coréennes (1959), będacy bogatą kompilacją materiałów wizualnych i tekstu, stanowiaca odpowiednik jego prac filmowych realizowanych od pierwszej połowy lat pięćdziesiątych. Historia prekursorów eseju filmowego obejmowałaby również wspomniane przez Corrigana filmy o charakterze edukacyjnym, ale również propagandowym: Kulturfilmy ${ }^{30}$, sowiecką szkołę montażu (w tym zwłaszcza prace Eisensteina i Wiertowa), czy lewicowe dokumenty lat trzydziestych powstające w Europie zachodniej (m.in. Kryzys, 1931-1932, zrealizowany dla Francuskiej Partii Komunistycznej czy Życie należy do nas, 1935 - film wyborczy Fontu Ludowego, projekt Stowarzyszenia Niezależnego Kina) i Stanach Zjednoczonych (dokumenty lewicowych kolektywów, zwłaszcza Frontier Film Group silnie inspirowanej sowiecką szkoła montażu).

${ }^{29}$ Zob. Michael Jennings, Agriculture, Industry, and the Birth of the Photo-Essay in the Late Weimar Republic, "October" 2000, Vol. 93, s. 23-56.

${ }^{30}$ Do dziedzictwa Kulturfilmu odwoływali się tacy autorzy jak Wiertow, ale też późniejsi eseiści, traktując ten nurt często jako negatywny punkt odniesienia - w akcie dekonstrukcyjnym. 
Jak już wspominałem, wśród badaczy eseju filmowego panuje ogólna zgoda co do tego, że „esej właściwy” pojawia się po II wojnie światowej - wraz z pracami francuskich autorów - Alaina Resnais, Chrisa Markera czy Agnes Vardy, a nieco później także Jean-Luca Godarda. W historii eseju filmowego to właśnie tu najbardziej zasadne byłoby odwoływanie się do kategorii dyspozytywu kinowego - w przeciwieństwie do wielu wspomnianych powyżej filmów edukacyjnych i lewicowej propagandy prace te pojawiały się w kinowym obiegu, były recenzowane i szeroko omawiane przez prominentną krytykę filmowa, i stanowiły ważny element rozwijajaccej się na przełomie lat pięćdziesiątych i sześćdziesiątych kultury kinofilskiej. Nieco inaczej przedstawia się późniejsza historia eseju filmowego - czy może raczej audiowizualnego; można by ja określić jako trwający do dziś okres „wyjścia z kina”.

Pod koniec lat sześćdziesiątych wielu autorów związanych dotąd silnie z dyspozytywem kinowym zaczyna realizować filmy, które wykraczaja radykalnie poza dominujące rozumienie tego czym, kiedy i gdzie jest film. Mowa tutaj o lewicowym kinie politycznym (walczacym). Filmy realizowane w ramach kolektywu Dziga Vertov Group, agitacyjno-propagandowe eseje Fernando Solanasa i Octavio Getino, francuskie filmy sytuacjonistyczne i inspirowane nimi niemieckie filmy Haruna Farockiego, to tylko niektóre przykłady kontr-kina będącego nie tylko próbą zanegowania dominującego modelu kina rozrywkowego, ale i autorskiego. Dodajmy, że ta negacja wykraczała poza kwestie estetyczne, przeformułowujac cały model produkcji, dystrybucji i sposobów prezentacji filmów. Przykładowo, we Francji zaniechano finansowania filmów z subsydiów państwowych i korzystania ze wsparcia finansowego oferowanego przez oficjalne instytucje kultury. Filmy powstawały poza strukturami przemysłu filmowego. Ostatecznie też zmienił się sposób ich wyświetlania. Filmy kolektywu Dziga Vertov Group coraz rzadziej można było obejrzeć w kinach, częściej w kinotece, salach uniwersyteckich, fabrykach czy podczas spotkań związków zawodowych i aktywistów. Filmy te nie były już adresowane do publiczności kina autorskiego, francuskiej nowej fali. Stanowiły nowy obszar „praktyki teoretycznej” i w tych kategoriach powinna być badana zarówno radykalna estetyka tych filmów, jak również historia nowego dyspozytywu, w ramach którego te filmy funkcjonowały.

Kolejnym okresem w historii audiowizualnej eseistyki jest druga połowa lat siedemdziesiatych ${ }^{31}$, a więc czas kiedy wielu eksperymentujących $\mathrm{z}$ językiem filmowym twórców dostało szansę realizacji awangardowych projektów w instytucjach telewizji publicznej, a nieco później także prywatnej. Filmy Godarda i Anne-Marrie Miéville, Edgardo Cozarinsky'ego czy Chrisa Markera, jak również wielu innych autorów kojarzonych powszechnie z nową falą francuska były w latach siedemdziesiątych i osiemdziesiątych produkowane przy współpracy Francuskiego Instytutu Audiowizualnego (INA). Wiele z nich zostało

${ }^{31}$ Jest to oczywiście data umowna - w drugiej połowie lat siedemdziesiątych widać faktycznie nasilenie w produkcji podobnych prac, ale już wcześniej można wskazać przykłady pojawiania się audiowizualnej twórczości eseistycznej w ramówkach telewizyjnych (zwłaszcza w BBC). 
później pokazanych publiczności telewizyjnej, co w założeniu autorów miało przekształcić dominujący model telewizji (telewizyjny dyspozytyw) umacniajacy hegemonię społeczeństwa spektaklu. „W założeniu” - ponieważ w praktyce warunki emisji produkowanych dla telewizji esejów audiowizualnych odbiegały często od autorskich założeń. Przykładowo seria Francja, zabawa dwojga dzieci (France/tour/detour/deux/enfants, 1977-1978) Godarda i Miéville miała być emitowana w cotygodniowym cyklu programów, które estetycznie nawiązywały do popularnych konwencji telewizyjnych. Ta mimikra była jednak pozorna. Wewnątrz krył się bowiem polityczny esej, który miał zmuszać widzów do konfrontacji z niewygodnymi problemami społecznymi i politycznymi. Dyrektorzy stacji nie zgodzili się jednak na pokazanie programów w zaproponowanej przez autorów formie. Cała seria została wyemitowana dwa lata później w popularnym telewizyjnym bloku „kina autorskiego”. W ten sposób zdezaktualizowano treść programów, a jednocześnie zmieniono ich status; to, co w założeniu autorów miało być programem - cząstką rozproszona w amorficznym strumieniu telewizyjnym - stało się filmem o wyraźnie zaznaczonych granicach diegetycznych. Dodajmy jeszcze - filmem indeksowanym czytelnie jako przykład kina autorskiego ${ }^{32}$. Przykład esejów audiowizualnych realizowanych dla telewizji pokazuje wyraźnie konieczność konfrontowania założeń teoretycznych i estetycznych z case studies odkrywajacymi pełniejszy obraz tego, jak faktycznie funkcjonowały te prace w ramach dyspozytywu „zimnego medium”.

Po okresie rozczarowania telewizją jako platforma dystrybucji myśli eseistycznej wielu autorów rozpoczęło współprace z instytucjami sztuki - muzeami i galeriami - jako nowa przestrzenią oferujaca komunikacje $\mathrm{z}$ widownią. $\mathrm{W}$ stosunku do kina i telewizji muzeum stanowiło odmienny rodzaj sfery publicznej, uruchamiało odmienne dyskursy i typy recepcji. Oczywiście inny status miało też prezentowane dzieło. Estetykę klasycznego (linearnego) filmu zastapiły struktury oparte na loopowaniu i montażu przestrzennym (instalacje wielokanałowe). Autorzy nawiazzywali do innych niż filmowe form - kolekcji, kompilacji, archiwów, atlasów. Zmieniła się nie tylko przestrzeń w jakiej prace były prezentowane, ale i digeza prac - a ostatecznie cały dyspozytyw ${ }^{33}$.

Ostatni rozdział w historii eseju filmowego jako historii dyspozytywów stanowiłyby wideo-eseje. W artykule poświęconym temu zjawisku Stanisław Liguziński zwraca uwagę, że określenie „wideo” jest dość umowne i wskazuje ono jedynie na prace realizowane współcześnie przy wykorzystaniu oprogramowania komputerowego do montażu i obróbki obrazu. Autor zwraca też uwagę na związaną z nowymi mediami łatwość dystrybucji takich wideo-esejów ${ }^{34}$. Prace opisywane dalej przez Liguzińskiego stanowia jednak nie tyle przykład wideo-eseistyki, ale raczej wideo-krytyki a często po prostu twórczości fanowskiej.

${ }^{32}$ Bartosz Zajac, Rewolucji w telewizji nie będzie. Subwersywny potencjat eseju wizualnego a rzeczywistość „zimnego medium”, „Panoptikum” 2012, nr 11, s. 149-161.

${ }^{33}$ Thomas Elsaesser, The Museum and the Moving Image: A Marriage Made at documenta?, [w:] Between Stillness and Motion: Film, Photography, Algorithms, ed. Eivind Rossaak, Amsterdam 2011, s. 109-112.

${ }^{34}$ Stanisław Liguziński, Wideoesej. Zapiski na marginesach, „Ekrany” 2012, nr 6 (10), s. 81. 
Kompilacje scen z „analizowanych” filmów rzadko bowiem wykraczaja poza proste unaocznienie tezy, która można by streścić w jednym zdaniu. Próżno tu szukać głębszej refleksywności medium, nie mówiąc o auto-refleksji. Nie oznacza to, że sama kategoria nie jest funkcjonalna, i że w internetowej sieci nie sa dystrybuowane audiowizualne eseje, tworzone przez mniej lub bardziej anonimowych twórców. Z pewnościa takie zjawisko istnieje i wymaga analizy. Częściowa próbę sproblematyzowania wideo-eseju podjęli uczestnicy konferencji „Stuff It. The Video Essay in the Digital Age”, która odbyła się w Zurychu w $2002^{35}$. Omówione tam prace z pewnością bronia się jako przykłady szeroko pojętej wideo-eseistyki. Niestety, autorzy wystapień ograniczyli się do przedstawienia zagadnień estetycznych i tematów eksplorowanych przez wybranych twórców, zabrakło natomiast umiejscowienia wideo-eseju w obszarze historii kina, eseju filmowego czy wideo-artu, a także teorii (nowych) mediów. Nie dowiedzieliśmy się też nic o nowych sposobach produkcji i dystrybucji tych prac, a to na tym („ekstra-tekstualnym”) obszarze manifestuje się najwyraźniej różnica między wideo-esejem a np. esejem filmowym.

Ukazywanie złożonych relacji między wykorzystywaną technologia, konkretnym tekstem, widownią, jak również aktualnymi trybami recepcji, a także instytucjami i otaczającymi kulturę filmowa dyskursami - a więc to, co należałoby rozumieć pod pojęciem historii dyspozytywów - pozwala wyjść ze ślepej uliczki badań nad esejem audiowizualnym, do której prowadza genologiczne taksonomie, tekstualne analizy, jak również monografie poszczególnych twórców. Propozycja Kesslera przedstawiona na przykładzie wczesnego kina z powodzeniem może służyć jako narzędzie analizy scalającej zagadnienia natury estetycznej i teoretycznej. W odniesieniu do tak amorficznego zjawiska, jakim jest esej audiowizualny, pozwoliłoby to na skonstruowanie narracji nadajacej mu kształt, jednocześnie bez ryzyka zredukowania jego różnorodności.

\section{Bibliografia}

Alter M. N., Marcel Ophuls' "November Days": German Reunification as 'Musical Comedy', "Film Quarterly" 1997, Vol. 51, No. 2.

Alter M. N., The Political In / visible in the Essay Film: Farocki's "Images of the World and Inscriptions of War", [w:] H. Farocki, Working on the Sight-Lines, ed. Th. Elsaesser, Amsterdam University Press, Amsterdam 2004.

Alter M. N., Projecting History: Non-fiction German Cinema: 1967-2000, University of Michigan, Ann Arbor 2002.

Alter M. N., Translating the Essay into Film and Installation, "Journal of Visual Culture" 2007, Vol. 6, No. 1.

Arthur P., Essay Questions: From Alain Resnais to Michael Moore, "Film Comment" 2003, Vol. 39, No. 1.

Astruc A., Narodziny nowej awangardy: kamera-pióro, przeł. T. Lubelski, [w:] Europejskie manifesty kina. Od Matuszewskiego do Dogmy. Antologia, wyb., wstęp i oprac. A. Gwóźdź, Wiedza Powszechna, Warszawa 2002.

${ }^{35}$ Publikacja pokonferencyjna: Stuff It: The Video Essay in the Digital Age, ed. Ursula Biemann, Zürich-New York 2003. 
Bazin A., Marker's "Lettere de Sibérie", [w:] idem, French Cinema from the Liberation to the New Wave, 1945-1958, ed. and transl. B. Cardullo, University of New Orleans Press, New Orleans 2012.

Bobowski S., O eseju filmowym. Na przykładzie „Iluminacji” Krzysztofa Zanussiego, „Studia Filmoznawcze" 1991, vol. X.

Cahiers du Cinéma. The 1950s: Neo-Realism, Hollywood, New Wave, ed. J. Hillier, Harvard University Press, Cambridge, MA 1985.

Corrigan T., The Essay Film: From Montaigne, After Marker, Oxford University Press, OxfordNew York 2011.

Der Essay Film: Äethetik und Aktuaität, red. S. Kramer, Th. Tode, UVK Verlag Konstanz University Press, Konstanz 2011.

Elsaesser Th., The Museum and the Moving Image: A Marriage Made at documenta?, [w:] Between Stillness and Motion: Film, Photography, Algorithms, ed. E. Rossaak, Amsterdam University Press, Amsterdam 2011.

Elsaesser Th., Nowa historia filmu jako archeologia mediów, przeł. G. Nadgrodkiewicz, „Kwartalnik Filmowy" 2009, nr 67-68.

Jennings M., Agriculture, Industry, and the Birth of the Photo-Essay in the Late Weimar Republic, “October” 2000, Vol. 93.

Kessler F., The Cinema of Attractions as Dispositif, [w:] Cinema of Attractions Reloaded, ed. W. Strauven, Amsterdam University Press, Amsterdam 2006.

Kłys T., Film fikcji i jego dominanty, Wydawnictwo Naukowe „Semper”, Warszawa 1999.

Liguziński S., Wideoesej. Zapiski na marginesach, „Ekrany” 2012, nr 6 (10).

Minh-ha T. T., Framer Framed, Routledge, New York 1992.

Montero D., Thinking Images: The Essay Film as a Dialogic Form in European Cinema, Peter Lang, Oxford-New York 2012.

Nichols B., Ideology and the Image: Social Representations in the Cinema and Other Media, Indiana University Press, Bloomington 1981.

Nowicka M., 'Urzadzenie', 'zastosowanie', 'uktad'... - kategoria dispositif u Michela Foucaulta, jej tłumaczenia i ich implikacje dla postfoucaultowskich analiz wtadzy, „Przegląd Socjologii Jakościowej" 2011, vol. 7, nr 2.

Post-theory: Reconstructing Film Studies, eds. D. Bordwell, N. Carroll, University of Wisconsin Press, Madison 1996.

Przylipiak M., Poetyka kina dokumentalnego, Wydawnictwo Uniwersytetu Gdańskiego, GdańskSłupsk 2004.

Rascaroli L., The Personal Camera: Subjective Cinema and the "Essay Film", Wallflower Press, London-New York 2009.

Richter H., Der Film Essay: Eine neue Form des Dokumentarfilms, [w:] Schreiben Bilder Sprechen: Texte zum essayistischen Film, red. Ch. Blumlinger, C. Wulff, Sonderzahl, Wien 1992.

Stuff It: The Video Essay in the Digital Age, ed. U. Biemann, Springer, Zürich-New York 2003.

Theorizing documentary, ed. M. Renov, Psychology Press, Minneapolis 1993.

White H., Zdarzenie modernistyczne, przeł. M. Nowak, [w:] idem, Proza historyczna, red. E. Domańska, Universitas, Kraków 2009.

Zając B., Rewolucji w telewizji nie będzie. Subwersywny potencjat eseju wizualnego a rzeczywistość „zimnego medium, „Panoptikum” 2011, nr 10. 